\title{
Engineering and geoecological assessment of soils salinity in Nukus using GIS technologies
}

\author{
Izzet Aimbetov*, and Ruslan Bekimbetov \\ Karakalpak Research Institute of Natural Science, 230100 Nukus, Uzbekistan
}

\begin{abstract}
The article presents the results of engineering and geoecological studies of the salinity of the soils of the city of Nukus to the ground water level. The results of observations of changes in the city's ground water level are presented. It was found that the increase of the water level leads to additional salinization of the soils, which worsens the ecological situation of the city, has a negative impact on green spaces and reduces the longevity of plants. According to the results of research, mapsschemes of salinization of the city's soil were compiled. Studies have shown that the soils of the territory of Nukus are saline and mainly belong to the chlorine-sulphate type of salinity.
\end{abstract}

\section{Introduction}

The city of Nukus is located in the southern part of Karakalpakstan (Uzbekistan), on the right bank of the Amu Darya, $800 \mathrm{~km}$ northwest of Tashkent (1255 km by road).

The southern and eastern parts of the city are surrounded by the Kyzylkum desert. The northern part of the city borders the Amu Darya Delta. The main canal Kizketken (Doslyk) and the Anasai canal (Kattagar) pass through the city. The area of the city is $222 \mathrm{sq} . \mathrm{km}$., the population is 317.3 thousand.

One of the ecological features of the city of Nukus is the salinity of the soil. The results of the studies show that there is an increase in the salinity of the soil. Studies show that the increase in soil salinity is due to an increase in the water level [1]. Increasing the salinity of the soil has a negative impact on the ecological situation of the city and reduces the survival rate of seedlings for landscaping the city, inhibits the growth of vegetation. For example, studies show that due to increased salinity in Karakalpakstan, the longevity of woody and shrubby plants decreases and the ecological balance is disturbed. This is observed throughout the entire territory of Karakalpakstan [1,2].

The analysis of the existing literature shows that the salinity of urban soils was mainly studied in relation to solving construction problems [4 -15].

Landscaping of Nukus is one of the urgent tasks, the solution of which will allow, will mitigate the impact of the hot climate. To increase the survival rate of seedlings and the effective implementation of measures for landscaping the city territory, it is necessary to have information about the nature and patterns of salinization of the soil-soils of the

\footnotetext{
*Corresponding author: izzet chf@mail.ru
} 
territory of Nukus. This information will allow you to effectively choose the type of plants for gardening, depending on the salinity of the soils.

The purpose of our work is drawing up a series of maps-schemes of salinization of the soils of the city of Nukus using GIS technologies that is necessary for the development of landscaping plans for the city of Nukus.

\section{MATERIALS AND METHODS}

The research results show that the ground water level is increasing in Nukus (Fig. 1). The analysis of the graph shown in Fig. 1 shows, that there is a change in the ground water level over the years. This is primarily due to the irrigation of this area and the filtration of water from the irrigation system, the main channels flowing through the city, as well as the insufficiency of the city's drainage system.

Analysis of archival materials of local engineering and geological organizations showed that in 1970, at the level of underground water 2-5 m, the salinity of underground water was $1.7 \mathrm{~g} / 1$, in 1986, the level of ground water rose to $0.3-2 \mathrm{~m}$, and the average salinity reached $18 \mathrm{~g} / 1$, in some cases up to $32 \mathrm{~g} / \mathrm{l}$. [1].

This circumstance indicates an increase in the aggressiveness of underground water, which in turn contributes to the suppression of green spaces. At the same time, the city of Nukus is not sufficiently provided with a drainage system.

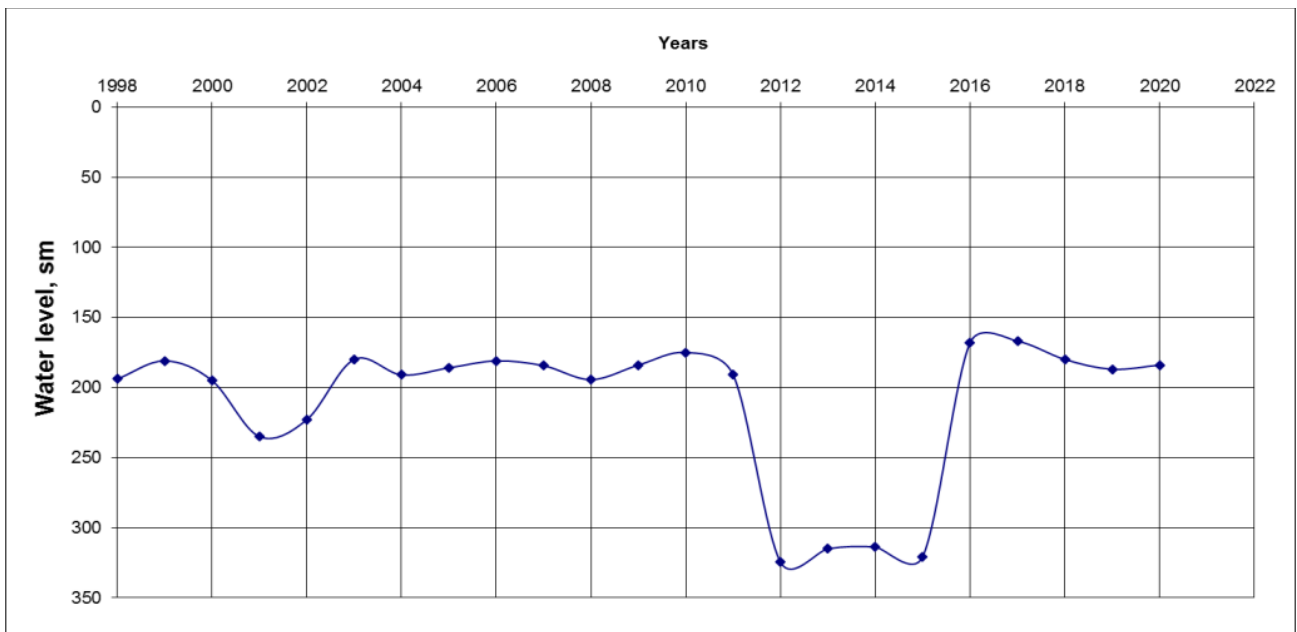

Fig. 1. Change in the underground water level of the city of Nukus

To prevent the aggressive effect of salts on green spaces, it is necessary to assess the regularity of salinization of the soils of the city of Nukus.

To assess the nature of the distribution of salts and to determine the types of salts that have a depressing effect on green spaces, maps of the salinity of the soils of Nukus were compiled. At the same time, conclusions on the engineering and geological conditions of the construction site of buildings, compiled by engineering and geological organizations, were used. As a rule, the reports on engineering and geological conclusions contain the results of chemical analysis of soils and ground waters according to their salinity. They are used to prevent the destructive effect on the underground parts of buildings and structures. To assess the ecological situation on the salinity of the territory of the city of Nukus, data from existing conclusions on engineering and geological conclusions of objects located in the city of Nukus were used. To assess the patterns of salt distribution on a digitized map at a scale of 1:50,000, the coordinates of the points where the salinity of the soil was 
determined to the level of underground water were plotted. The maps are compiled using the ArcGIS computer program. When drawing up the maps, the results of determining the salinity of the soils of 127 wells lying up to the level of underground water were processed. The research area is $90 \mathrm{sq}$. $\mathrm{km}$. When drawing up the maps, a map at a scale of 1:50,000 was used as the basis.

\section{RESULTS AND DISCUSSION}

Figure 2 shows a map-scheme of soil-soil salinization, describing the nature of salinization, the analysis of which shows that the soils by types of salinization are mainly of the chloride-sulfate type.

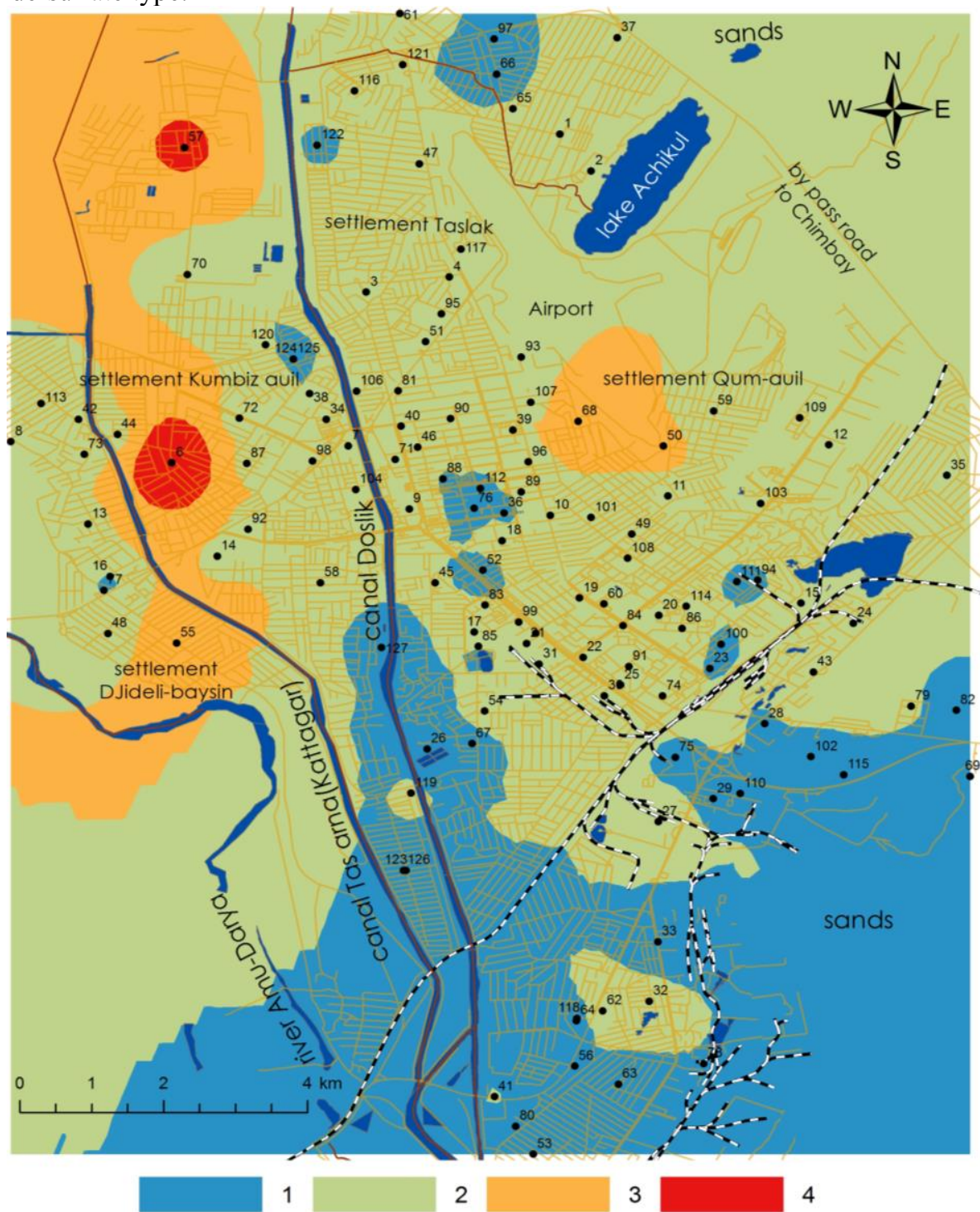

Fig. 2 Map-scheme of salinization of the soils of the city of Nukus (up to the level of underground water) by types of salinization (ratio of $\mathrm{Cl} / \mathrm{SO} 4$ ions)

1 - 0.04-0.2 (sulphate); 2 - 0.2-1 (chloride-sulfate); 3 -1-2 (sulphate-chloride); 4 - 2-4.781 (chloride); - wells 
Figure 3 shows a map of the salinization of the soils of the city of Nukus to the level of underground water, reflecting the degree of salinization of the soils. The analysis of the map shows that according to the classification of V. M. Bezruk et al. [2] according to the degree of salinity, soils belong to the weakly saline and saline types.

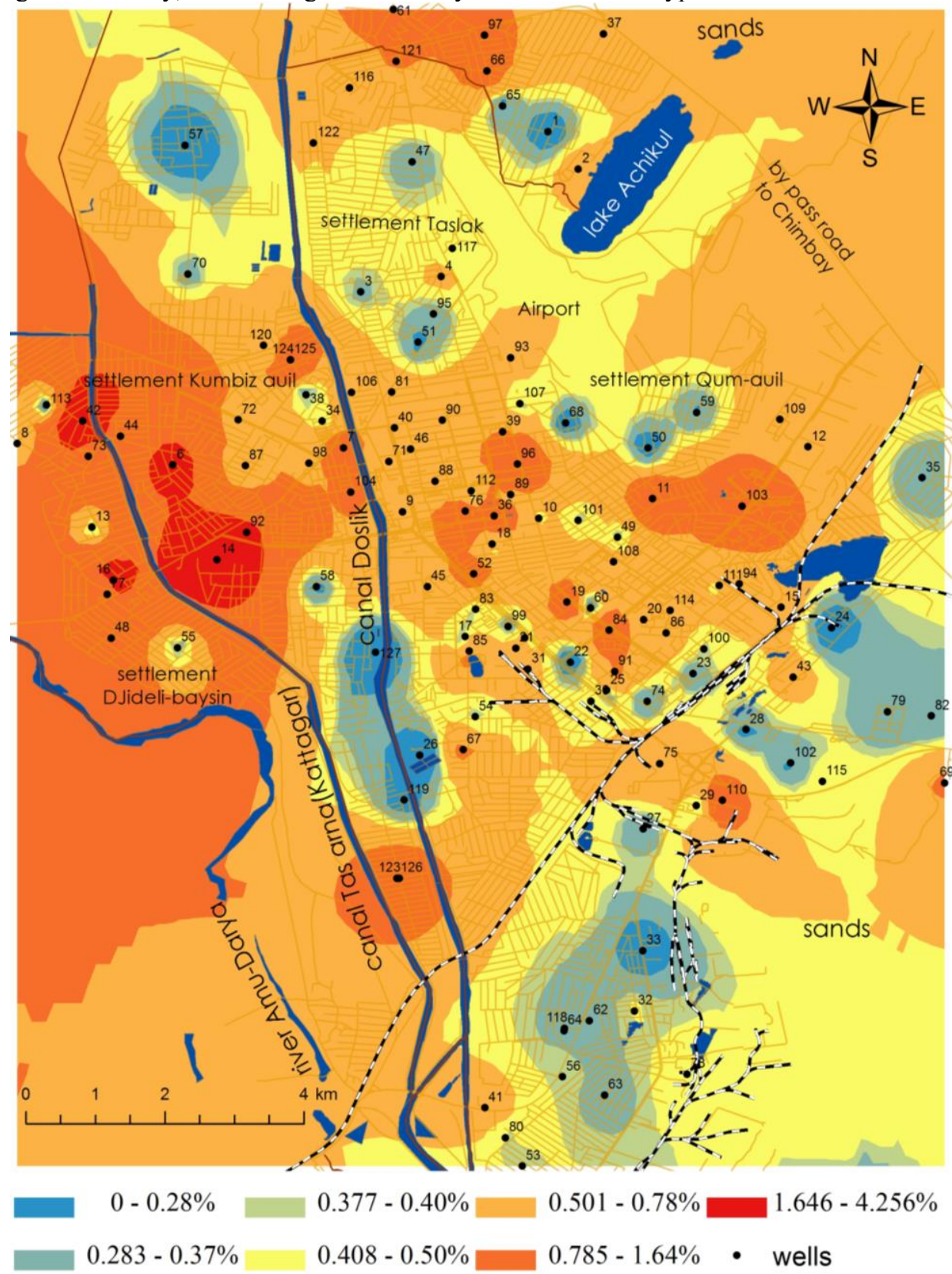

Fig. 3 Map-scheme of salinization of the soils of the city of Nukus (up to the level of underground water), \%

Different types of green spaces react differently to the types of water-soluble salt ions. In this regard, we have constructed similar maps of the salinity of the soils of Nukus in terms of the content of chlorine and sulfate ions in them. (Figure 3-5). These maps can be 
used when choosing the type of vegetation for landscaping the city territory and developing measures for the landscape design of Nukus. At the same time, for greening the city territory in the most saline places, it is necessary to use salt-resistant plants. In less saline areas, less salt-tolerant plants should be planted. This will improve the microclimate, the ecological situation and create more comfortable conditions for the residents of the city. It should be noted that salt-tolerant plants lead to a decrease in soil salinity. After the soil is desalinated, less saline-resistant trees can be planted in these areas.

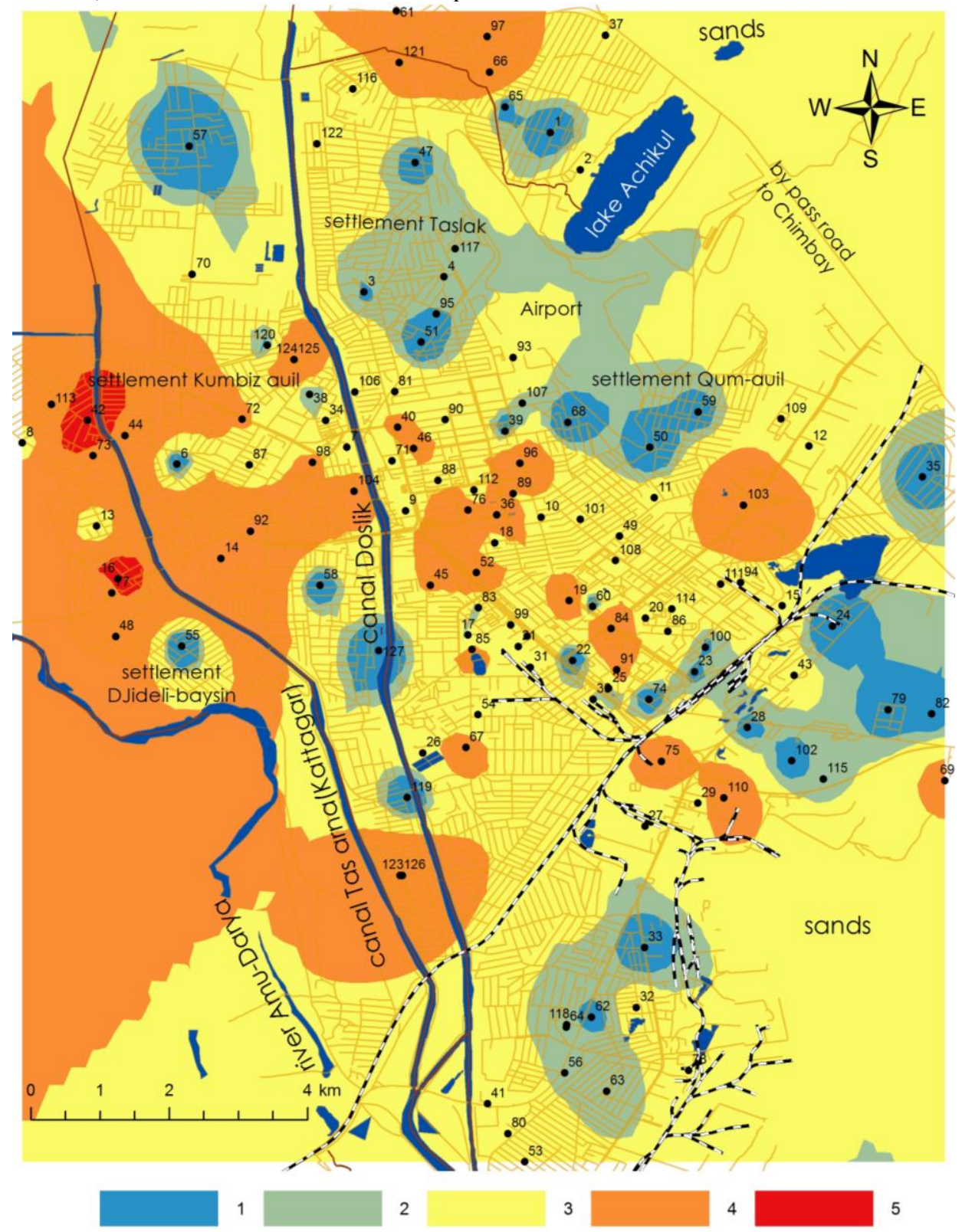

Fig. 4 Map-scheme of salinization of the soils of the city of Nukus (up to the level of underground water) by the content of $\mathrm{SO} 4 \mathrm{in} \mathrm{mg} / \mathrm{kg}$

1- 49-1524; 2 - 1524.1-1976; 3 - 1976.6-3500; 4 - 3500.7-8633; 5 - 8633.5-25920; •-wells 


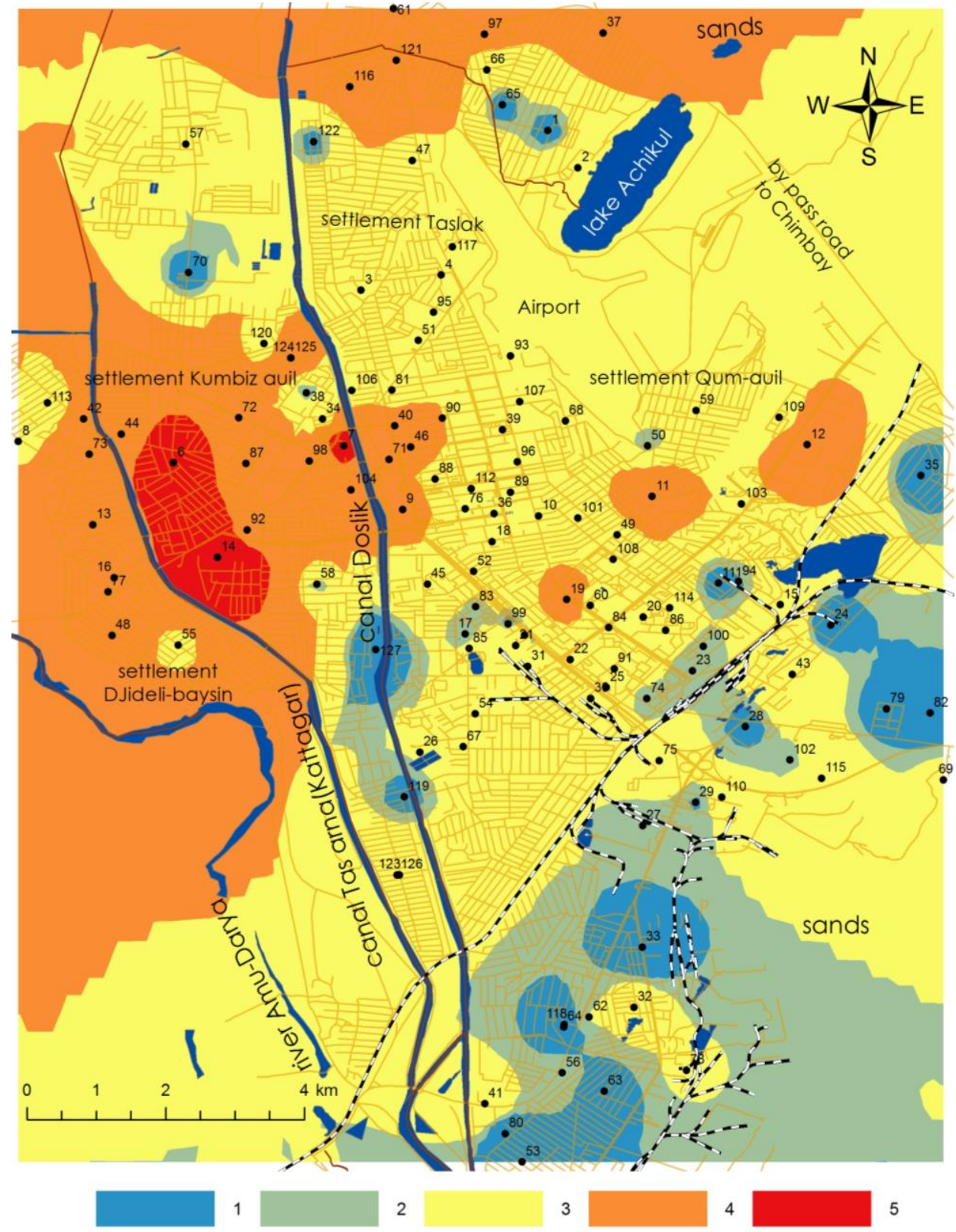

Fig. 5 Map-scheme of salinization of the soils of the city of Nukus (up to the level of underground water) by the content of chlorine ions in $\mathrm{mg} / \mathrm{kg}$ 1 - 36-469; 2 - 469.5-580; 3 - 580.8-1050; 4 - 1050.4-3030; 5 - 3030.4-11380; • - wells

Unfortunately, currently in Karakalpakstan there are no specific recommendations for the cultivation of trees and other green spaces in saline areas. This makes it difficult to choose the type of trees to plant in order to improve the microclimate of the city of Nukus. 


\section{CONCLUSION}

1. The results of the research showed that in the city of Nukus, due to the increase in the level of underground water, there was an increase in the level of salinity of the soils. The salinity of soils and underground waters is mainly of chloride and sulfate characters.

2. The analysis of the results of existing studies has shown that the salinity of soils was studied mainly to solve the issues of construction of buildings and engineering structures.

3. For effective greening of the city of the territory of Nukus, it is necessary to develop scientific recommendations for the selection and placement of tree species, depending on the salinity of the soil of the territory of the city of Nukus.

4. In order to improve the environmental situation of the city of Nukus, it is necessary to conduct research and development work for the design of a new innovative drainage system.

\section{References}

1. I.K. Aimbetov, Stroitelstvo soorujeniy na zasolennıx gruntax Respubliki Karakalpakstan, (Ilim 2014)

2. V.D. Lomtadze, Ingenernaya geologiya. Ingenernaya petrologiya (Nedra, Leningrad, 1985)

3. A.A. Rafikov, B.A. Bakhritdinov, Soviet Soil Science, 10, 98-100 (1982)

4. I.K.Aimbetov, R.T.Bekimbetov, IJSR, 9(7), 504-507 (2020)

5. E.R uis-Agudo, F. Mees, P. Jacobs, C. Rodriguez-Navarro, Env. geol. 52(2), 305-317 (2007)

6. E.E. Alonso, S. Olivella, 12th International Conference on Computer Methods and Advances in Geomechanics, 2, 891-910 (2008)

7. M. Angeli, J.P. Bigas, D. Benavente, B. Menéndez, R. Hébert, C. David, Env. Geol., 52(2), 187-195 (2007)

8. P.H. Cosenza, M. Ghoreychi, B. Bazargan-Sabet, de G. Marsily, Int. .J Rock Mecs and min. Scs., 36(4), 509-526 (1999)

9. O. Johanson, I.K. Aimbetov, J. Jerker, J. of Mar. sys., 76(3), 287-295 (2009)

10. Y.P. Li, C.H. Yang, Q.H. Qian, D.H. Wei, D.A. Qu, Proceedings of the 6th conf. on the mech .behavior of salt "SALTMECH6 - the mechanical behaviour of saltunderstanding of THMC processes in salt, 69-74 (2007)

11. W.G. Liang, C.H. Yang, Y.S. Zhao, M.B. Dusseault, J. Liu, Int. J. Rock Mech. Min. Sc. 44(3), 400-411 (2007)

12. Li Min, Chai Shouhi, Du Hongpu, Wang Cnen, The Japanese Geotech. Soc. Soils and Foundation; 56(3), 327-335 (2016)

13. S.A. Naeiny, M.A. Jahanger, A. Monshi, Proceeding of the 5th Int. Sym. on def. characterics of geomat., 500-505 (2011)

14. T. Schulze, H.K. Popp, Eng. Geol. J., 61 (2/3) (2001)

15. H. Yang, Y.P. Li, F. Chen, X.L. Shi, D.A. Qu, Proceedings of the 43rd U.S. rock mech. Sym. and 4th U.S. Canada rock mech. Sym., 450-455 (2009) 